This is the final peer-reviewed accepted manuscript of:

V. Madonna, A. Walker, P. Giangrande, G. Serra, C. Gerada and M. Galea, "Improved Thermal Management and Analysis for Stator End-Windings of Electrical Machines" in IEEE Transactions on Industrial Electronics, vol. 66, no. 7, pp. 5057-5069, July 2019 The final published version is available online at:

https://doi.org/10.1109/TIE.2018.2868288

Rights / License:

The terms and conditions for the reuse of this version of the manuscript are specified in the publishing policy. For all terms of use and more information see the publisher's website.

This item was downloaded from IRIS Università di Bologna (https://cris.unibo.it/)

When citing, please refer to the published version. 


\title{
Improved thermal management and analysis for stator end-windings of electrical machines
}

\author{
Vincenzo Madonna, Student Member, IEEE, Adam Walker, Member, IEEE, Paolo Giangrande, \\ Giovanni Serra, Senior Member, IEEE, Chris Gerada, Senior Member, IEEE, \\ and Michael Galea, Senior Member, IEEE
}

\begin{abstract}
In electrical machine design, thermal management plays a key role in improving performance and reducing size. End-windings are commonly identified as the machine hot-spot. Hence, lowering and predicting end-windings temperature are crucial tasks in thermal management of electrical machines. This paper proposes and investigates a non-invasive but effective cooling method that aims for a uniform cooling of a machine's winding by implementing direct cooling on its end-windings. Modelling and experimental results show that a $25 \%$ hot-spot temperature reduction on a particular application can be achieved. To analyse the proposed technique in detail, an accurate but computationally-economic lumped parameter thermal network is developed. Comparison between a 'standard' thermal network and its simplified equivalent (with less nodes) is presented where the models are developed and fine-tuned based on experimental data. All the above is used to investigate the potential of the proposed end-winding cooling method with different configurations of the methodology.
\end{abstract}

Index Terms - Electrical Machines, End-windings, Lumped Parameter Thermal Network, Thermal Management

\section{INTRODUCTION}

$\mathrm{E}$ LECTRIFICATION in mobile applications, such as for aerospace and automotive systems mainly aims to improve air quality by reducing greenhouse gas emissions, and cutting down toxic particles [1-3]. In this field, high performance electrical machines are required to meet power density and reliability requirements. Electrical machine design is constrained by three main factors, namely the electromagnetic, the mechanical and the thermal limits [4]. The ever-increasing demand for higher power and torque densities, enabled by advances in materials and design tools, is resulting in the thermal limit nowadays becoming more and more the dominant constraint. For this reason, appropriate thermal management is required for avoiding over-temperatures. As a rule of thumb, a $10^{\circ} \mathrm{C}$ increase in temperature halves the insulation system lifetime $[5,6]$. Examples of improvements in power and torque densities, by

Manuscript received February 02, 2018; revised April 04, 2018, and July 04, 2018; accepted August 14, 2018. This work was funded by the INNOVATIVE doctoral programme. The INNOVATIVE programme is partially funded by the Marie Curie Initial Training Networks (ITN) action (project number 665468) and partially by the Institute for Aerospace Technology (IAT) at the University of Nottingham. This work was also partially funded by the University of Nottingham Propulsion Futures Beacon. (Corresponding Author: Michael Galea)

V. Madonna, A. Walker, P. Giangrande, C. Gerada and M. Galea are with the Power Electronics, Machines and Control (PEMC) group, University of Nottingham, Nottingham, NG72RD, UK (e-mails: eexvm3@nottingham.ac.uk; ezzadw1@nottingham.ac.uk; ezzpg@ nottingham.ac.uk; eezcg@nottingham.ac.uk; ezzmg@nottingham.ac.uk).

G. Serra is with the Department of Electrical, Electronic and Information Engineering "Guglielmo Marconi," University of Bologna, 40126 Bologna, Italy (e-mail: giovanni.serra@unibo.it)

M. Galea and C. Gerada are also with the University of Nottingham Ningbo China, Ningbo 315100, China means of thermal management, are given in [7-10]. An advantage resulting from lowering the winding temperature is represented by the reduction of the winding's electrical resistance, which leads to lower copper losses (i.e. better efficiency) for a given current density [11]. Conversely, a proper thermal management allows higher current densities for a given winding temperature limit (which depends on the insulation thermal class), which can result in higher torque for the same machine's size. Overall, improving the thermal management provides more freedom at the design stage.

In general, the heat produced within the windings is difficult to extract, since the combined effects of the slot liner, and the wire insulation and any trapped air significantly increase the equivalent thermal resistance from the centre of the coils to the cooling agent and/or surface [12]. Conventional air cooling systems, such as shaft-mounted fans, housing fins or external fans, are very effective. However, for high power density machines, with elevated current densities, they may not be enough to guarantee adequate cooling, including in the centre of slots or coils. Consequently, advanced cooling methods, employing either high thermal conductivity fluids or high thermal conductivity insulation materials, have recently also become popular [13]. A common technique for cooling improvements is through the use of forced liquid cooling methods involving channels, ducts or water jackets. Such methods provide excellent cooling within the active region of windings [14]. However, very often they do not have the same effect towards the endwindings, resulting in the hot spot being localised in this area of the machine [15-17].

The current state of the art for end-windings cooling is mainly represented by either spray cooling [18-20] or flooded stator $[21,22]$. Both these methods produce very high heat dissipation in the end-windings region, since the cooling fluid is directly in contact with the winding surface. Nevertheless, spray cooling suffers reliability and robustness issues, due to corrosion and erosion of spray nozzles [23]. Also, the nozzle blockage might constitute a single-point failure. Both methods (i.e. spray cooling and flooded stator) increase the design and construction complexity of the machine, which adds cost to the system. Furthermore, while they are advantageous when implemented on large size motors; in smaller size electrical machines, where space and cost are significant limiting factors, they are less suitable. For these applications, a low thermal resistance pathway, between end-windings and stator housing (in both axial and radial directions), can be established by using a potting compound. The effectiveness of this method is heavily dependent on the thermal conductivity of the adopted compound material, which is directly related to its price. The end-windings potting compound is combined together to another cooling method, 
such as water jackets or air forced convection, in order to enhance its cooling effect [24]. Potting compounds also add a non-negligible mass to the electrical machine.

In [25] and [26] the heat produced within the stator windings of an axial flux machine is extracted by embedding cooling tubes in a custom made Litz wire. A similar approach is described in [27] where a cooling pathway is incorporated in the stator slot and the windings utilise flat wires. Both these methods provide excellent cooling capabilities. Nonetheless, they are applied to non-conventional windings construction (i.e. Litz wires for axial flux machines and flat wire windings). Thus, if applied to radial flux random-wound electrical machines, the slot fill factor could be compromised and the manufacturing complexity would significantly increase.

In light of the above, this paper introduces an innovative cooling method, which directly cools the stator end-windings of radial flux, random wound electrical machines, through a dedicated liquid-carrying pipe. The proposed cooling method (PCM) is very cost-effective and can be applied to existing machine design, or product line which has a fixed stator lamination geometry. Indeed, the stator core can be wound or rewound if sufficient axial space is available.

After describing the PCM in Sections II and III, the cooling capability of the PCM is proven by experimental results carried out on a purposely built test-rig reported in Section IV. In Section VI an analytical trade-off study, based on results from a lumped parameter thermal network (LPTN) is performed in order to select the most suitable pipe material. The LPTN used during the trade-off study is a simplified version obtained from a highly-discretised LPTN illustrated in Section V. In order to achieve accurate temperature estimation, both LPTNs are experimentally fine-tuned and the comparison between their performances is presented.

\section{Proposed CoOling Method}

In forced liquid-cooled machines the winding hot-spot is often located in the end-windings $[15,16]$, mainly due to the high thermal resistance between the coils and the cooling agent. If not properly cooled, end-windings are exposed to excessive temperatures, which can and will cause failure in the insulation system [28].

The technique proposed in this paper aims to reduce the thermal resistance between the end-windings and the cooling agent, by directly cooling the end-windings. A pipe containing cooling fluid is directly placed/applied onto the end-windings surface to quickly extract the heat locally generated. This provides an additional cooling pathway to the heat produced in the slot (i.e. promoting axial heat transfer by taking advantage of copper's excellent thermal conductivity in the axial direction). Fig. 1 shows how maximisation of the contact area between pipe and end-windings is achieved with the end-windings being split into upper and lower sections.

Splitting the end-windings automatically doubles the heat exchange surface, and thus enhancing the cooling capability. Although splitting the end-windings incurs the cost of an extended length, it will be shown that the cooling capability improvement outweighs this drawback. The PCM is simple and cheap to implement and can be used on most conventional machine stators. It is worth underlining that the PCM is particularly suitable for concentrated windings, although it could theoretically be applied to any winding configuration.

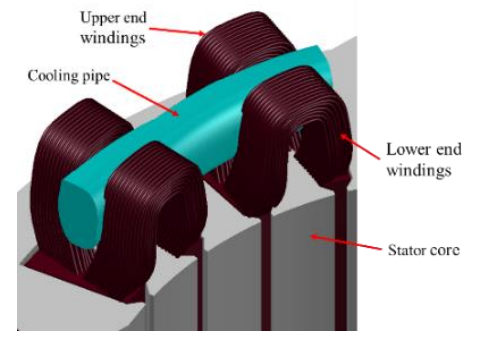

Fig. 1. Split end-windings with cooling pipe passing through.

\section{Preliminary Choice Of CoOling PiPe Material}

The PCM is mainly related to the use of a cooling pipe directly applied to the end-windings. This section is therefore dedicated to qualitative considerations on the pipe structure, the potential materials to be used and their thermo-mechanical properties.

\section{A. Pipe features}

Apart from the heat exchange surface between pipe and end-windings, the cooling capability of the PCM depends on the pipe features. In particular, the pipe wall thickness $t_{\text {pipe }}$ and the thermal conductivity of the pipe material $k_{\text {pipe }}$ strongly affect the cooling performance. In order to make an appropriate choice, a number of potential pipe materials are preliminarily investigated. The list of the considered cooling pipe materials is reported in TABLE I, together with their respective thermo-mechanical properties [29, 30], electrical conductivity $\sigma$ and maximum operating temperature $\vartheta_{\text {Max }}$ (i.e. temperature which guarantees at least 20,000 hours of safe operation). In TABLE I, the material flexibility is accounted through the Young's Modulus $E_{\text {pipe }}$, while a parameter, here called the contact factor $c f$, is introduced for quantifying the contact surface between cooling pipe and end-windings. This $c f$ is set in the range of 0 to 1 and it is defined in (1), where $A_{c t}$ is the ideal heat exchange surface between pipe and end-windings (i.e. contact surface), while $A_{e w}$ is the available cooling area of the end-windings. More details regarding the $A_{\text {ew }}$ calculation are provided in Part C of Section V.

$$
c f=A_{c t} / A_{e w}
$$

TABLE I

List of Potential CoOling PiPe Materials AND Their Properties

\begin{tabular}{|c|c|c|c|c|c|c|}
\hline Material & $\begin{array}{c}\sigma \\
{[\mathrm{MS} / \mathrm{m}]}\end{array}$ & $\begin{array}{l}\boldsymbol{\vartheta}_{\operatorname{Max}} \\
{\left[{ }^{\circ} \mathbf{C}\right]}\end{array}$ & $\begin{array}{c}\boldsymbol{k}_{\text {pipe }} \\
{[\mathrm{W} / \mathbf{K} / \mathbf{m}]}\end{array}$ & $\begin{array}{c}E_{p i p e} \\
{[\mathrm{GPa}]}\end{array}$ & $\begin{array}{c}t_{\text {pipe }} \\
{[\mathrm{mm}]}\end{array}$ & $\begin{array}{l}c f \\
{[-]}\end{array}$ \\
\hline PVC & Diel. & 100 & 0.19 & $2.4-4.1$ & 2 & 0.2 \\
\hline ABS & Diel. & 100 & 0.17 & $2-2.6$ & 2 & 0.2 \\
\hline PTFE & Diel. & 260 & 0.25 & $0.4-1.8$ & 2 & 0.25 \\
\hline $\begin{array}{l}\text { Silicone } \\
\text { Rubber }\end{array}$ & Diel. & 200 & 1.22 & $\begin{array}{c}0.001- \\
0.05\end{array}$ & 0.5 & 0.5 \\
\hline Nylon & Diel. & 70 & 0.25 & $2-4$ & 2 & 0.2 \\
\hline $\begin{array}{l}\text { Copper } \\
\text { (square) }\end{array}$ & 58.5 & $>500$ & 385 & 117 & 2 & 0.15 \\
\hline $\begin{array}{l}\text { Copper } \\
\text { (round) }\end{array}$ & 58.5 & $>500$ & 385 & 117 & 1 & 0.1 \\
\hline $\begin{array}{c}\text { Stainless } \\
\text { Steel }\end{array}$ & 1.35 & $>500$ & $12-45$ & $\begin{array}{l}190- \\
203\end{array}$ & 1 & 0.1 \\
\hline Aluminium & 36.9 & $>500$ & 204 & 69 & 1 & 0.1 \\
\hline Ceramic & Diel. & $>500$ & $5-15$ & 360 & 1 & 0.1 \\
\hline Glass & Diel. & $>500$ & 1.05 & $50-90$ & 2 & 0.1 \\
\hline $\begin{array}{c}\text { Carbon } \\
\text { Fibre }\end{array}$ & Diel. & 100 & $5-7$ & 150 & 1 & 0.1 \\
\hline
\end{tabular}

For some materials such as silicone rubber, round PTFE, round copper and square copper, $c f$ has been quantified through experimental measurements. For other materials it has been estimated based on the material's flexibility compared to those tested. 


\section{B. Potential pipes}

Among the materials listed in TABLE I, metals present the highest thermal conductivity and can withstand elevated temperatures. However, they are characterised by low flexibility and therefore cannot provide a large contact surface with the end-windings. Additionally, a metallic pipe would be dangerous in the case of winding insulation breakdown. Hence, precautions must be used, which would add extra thermal barriers (e.g. pipe insulation coating). Another drawback of electrical-conductive pipes is represented by the induced AC current in the pipe caused by the variable magnetic field in the end-windings region. Ceramic and glass materials mitigate the electric risk and are not subject to induced AC current, but they are difficult to shape. Poly Vinyl Chloride (PVC) and Acrylonitrile Butadiene Styrene (ABS) are very common plastic pipe materials. Despite a fair flexibility, which would provide a moderate heat exchange surface, these materials have poor thermal conductivity and $2 \mathrm{~mm}$ is the minimum wall thickness available on the market. Further, the maximum operating temperatures of both PVC and ABS are too low for the application under analysis. Although plastic materials, such as Polytetrafluoroethylene (PTFE), Perfluoroalkoxy Alkane (PFA) and Polysiloxanes (commonly known as silicone rubber), have a thermal conductivity two orders of magnitude lower than metals, they are characterised by an outstanding chemical stability at elevated temperature [30]. According to the silicone pipe manufacturer, a lifetime of 20,000 hours is guaranteed for continuous operations at $200^{\circ} \mathrm{C}$. Thus, it is expected that operating the pipe below $180^{\circ} \mathrm{C}$ (i.e. thermal class of the machine's insulation), it would easily achieve the declared lifetime. Besides, some plastic materials (e.g. PTFE) can be thermoformed, in order to be fitted in the end-windings. This property can be exploited for maximising the heat exchange surface, but requires prior knowledge of the exact endwindings geometry.

\section{Achieving the optimal heat exchange area}

Compared to other plastic materials, silicone rubber pipes have the thinnest wall thickness (i.e. $0.5 \mathrm{~mm}$ ). Furthermore, silicone rubber is very flexible and expands when carrying pressurised fluid. Due to its expansion, silicone rubber fills the uneven surface of the end-windings ensuring a significant contact surface. This effect is graphically sketched in Fig. 2, where the potential expansion for metallic, PTFE and silicone rubber pipes is visually shown.
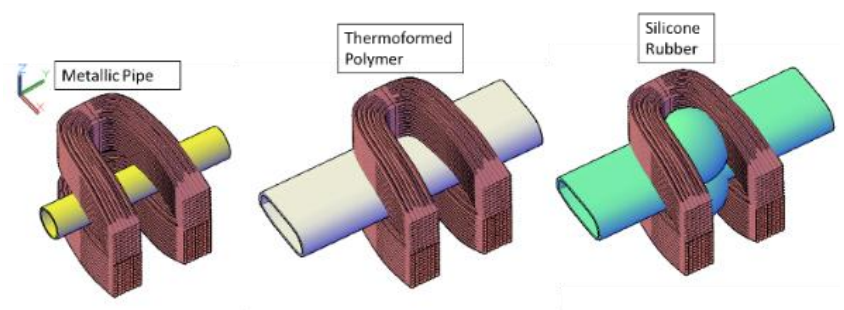

Fig. 2. Comparing heat exchange surface for different materials.

As depicted in Fig. 2, the maximum contact area is achieved with the silicone rubber pipe, which achieves a contact factor of up to 0.5 . PTFE and round metal pipes only achieve 0.25 and 0.1 respectively. A contact factor of 0.5 means that half of the ideal cooling area of end-windings is in contact to the pipe (i.e. it acts as heat exchange surface). Fig. $3 \mathrm{a}$ illustrates the heat exchange surfaces for silicone rubber, while PTFE and round metal pipes are shown in Fig. $3 \mathrm{~b}$ and
Fig. 3c respectively. This preliminary qualitative analysis shows that the silicone rubber is the most suitable pipe material for the PCM. For this reason, the experimental tests are performed on a motorette equipped with silicone rubber pipe. The quantitative analysis of the pipe materials is carried out once the LPTN is built and experimentally fine-tuned.

In order to enhance the heat exchange surface and thus improve the effectiveness of the PCM, the axial section of the end-windings needs to be purposely elongated. For the analysed machine it was necessary to extend the axial portion of the end-windings to a factor 2.66 (approx. 15mm) with respect to the original windings layout, as reported in Fig. 4. Clearly, the end-winding extension causes an increase in the Joule losses and machine length. However, once the PCM is applied, this loss increment is compensated by the overall coils' temperature (and therefore electrical resistivity) reduction as it will be discussed in Section IV. Further, the coils' temperature lowering (due to the PCM application) leads to an increased potential current density $\mathrm{J}$, which allows to outweigh the extra machine length improving the power density.
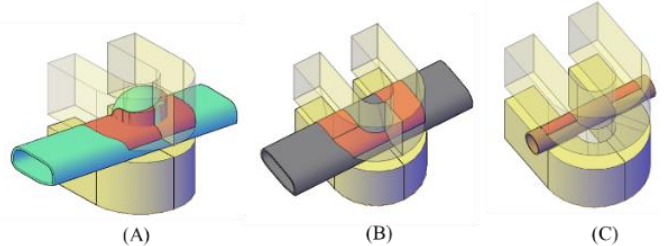

Fig. 3. Heat exchange surface between end-windings and pipe (orange area).

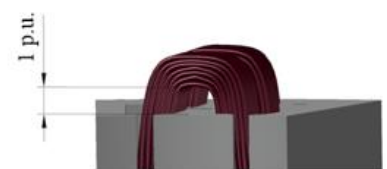

(a)

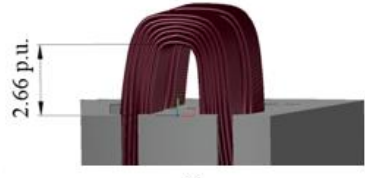

(b)
Fig. 4. End windings length comparison; a) original configuration (i.e. without the PCM) and b) modified configuration (i.e. with the PCM).

\section{Validation of the Proposed Methodology}

To test the proposed concept, an existing electrical machine $[31,32]$ is considered. This $30 \mathrm{~kW}, 2800 \mathrm{rpm}$ machine was developed for an automotive traction application (i.e. a hybrid electric car), where the same cooling system employed for the internal combustion engine is used for cooling the electric motor. The original machine was cooled through a stator water jacket, and a total flow rate of $10 \mathrm{~L} / \mathrm{min}$ was available from the cooling system. An experimental analysis has proven that the hot-spot temperature difference is smaller than $5^{\circ} \mathrm{C}$, when the housing water jacket is supplied with $10 \mathrm{~L} / \mathrm{min}$ or $6 \mathrm{~L} / \mathrm{min}$. Thus, it was decided to utilise $6 \mathrm{~L} / \mathrm{min}$ for the housing water jacket and $4 L / m i n$ for the PCM (i.e. $2 L / m i n$ for the drive end pipe and $2 L / \mathrm{min}$ for the non-drive end pipe).

To facilitate the testing of the PCM, a motorette representative of the original machine was built and wound with $15 \mathrm{~mm}$ longer end-windings. It comprises six slots with three wound teeth (i.e. concentrated winding and alternated teeth layout). The three coils are made of class 180 nonimpregnated round enamelled magnet wire, with a diameter of $1 \mathrm{~mm}$. A further galvanic separation between coils and stator core is provided by a single layer of Nomex paper (i.e. slot liner). The resulting slot fill factor is equal to 0.45 .

The motorette's windings are fed by a DC power supply, hence only DC copper losses (easy to be determined) are 
generated during the test campaign. For cost saving reason and due to the absence of iron losses, the motorette was manufactured of solid steel via electrical discharge machining. Adopting the solid motorette core would not permit an accurate representation of the losses (i.e. the iron losses are neglected), although the exact loss magnitude and location are ensured. The main goal of the experimental test campaign is represented by the identification of the motorette uncertainties, such as the thermal conductivities and contact factors.

Similarly to the real machine, the motorette's main cooling circuit is a conventional water jacket embedded in the stator housing, which is made of aluminium. Three rectangular-shaped flow channels are distributed along the axial direction and each of the three channels is supplied with $1 / 3^{\text {rd }}$ of the total flow rate available for the stator water jacket cooling. This construction is representative of the actual machine assembly, where a spiral water jacket with three flow channels is employed. The proposed 'pipes on the end-windings' methodology are then implemented onto the motorette, with the selected pipe as concluded in Section II being of a silicone material. A block diagram showing the overall scheme is reported in Fig. 5, whilst the process of physical insertion of the cooling pipe in the end-windings is given in Fig. 6.

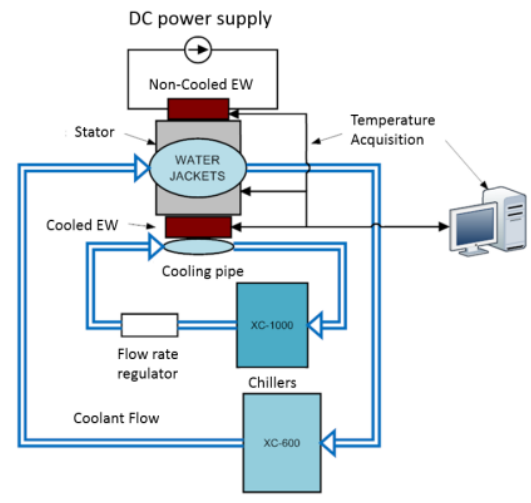

Fig. 5. Block diagram of the experimental setup.

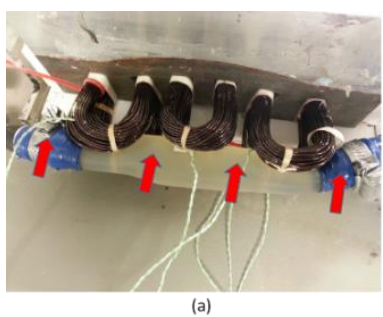

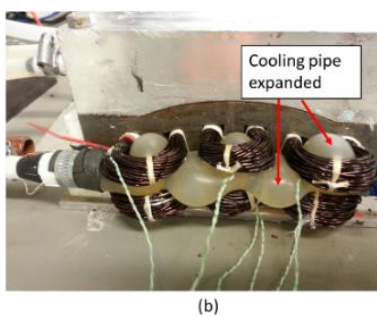

(b)
Fig. 6. Application of the silicone rubber pipe; a) insertion of the nonexpanded pipe and $b$ ) pipe expansion due to the flow rate increase.

The experimental setup for the test campaign is pictured in Fig. 7. The silicone rubber pipe is applied only on one side of the end-windings (i.e. drive end) and the cooling flow is controlled through a flow rate regulator. The temperatures within the slot and on the end-windings are measured using K-type thermocouples and recorded by a data logger. The testing regime consists of feeding the windings with various DC currents and recording the temperature values for both the original configuration (i.e. cooling only through the water jacket) and the configuration when the cooling on the endwindings is also applied. The exact same tests are performed for both configurations adopting $2 \mathrm{~L} / \mathrm{min}$ flow rate for the drive end pipe (i.e. PCM). The measured slot $\theta_{s}$ and end-windings $\theta_{\text {ew }}$ temperatures at steady-state are compared in Fig. 8.

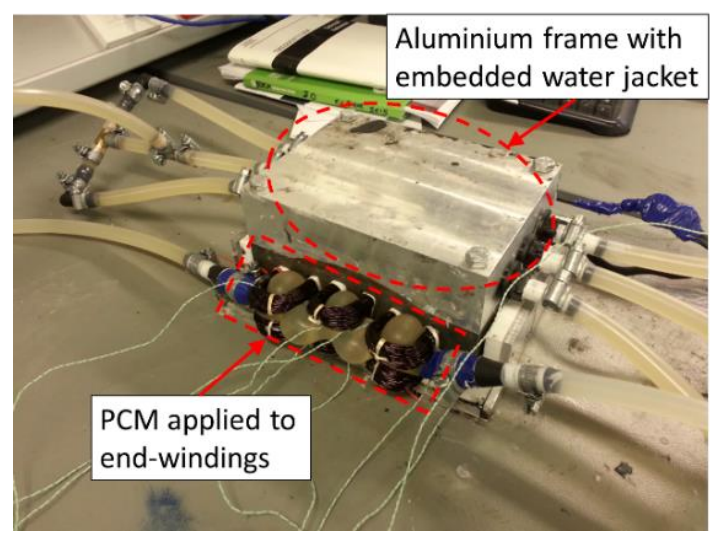

Fig. 7. Motorette equipped with silicone rubber pipe.

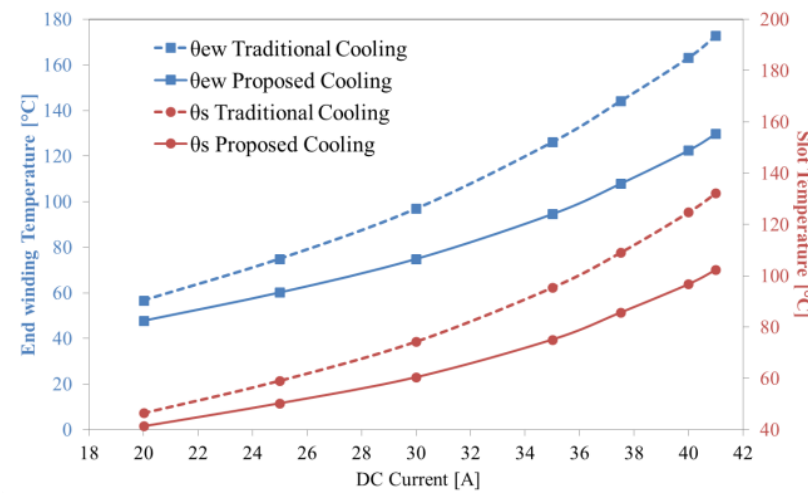

Fig. 8. Slot $\theta_{\mathrm{s}}$ and end-windings $\theta_{\mathrm{ew}}$ steady-state temperatures with (solid line) and without (dashed line) using the PCM.

The motorette winding insulation has thermal class of $180^{\circ} \mathrm{C}$ and this value was assumed as upper temperature limit for avoiding damage or lifetime shortening to the insulation. From Fig. 8, it can be observed that for the first configuration (water jacket only cooling), a DC current of $41 A$ resulted in an end-windings steady-state temperature of $172^{\circ} \mathrm{C}$. Comparing the temperature for the same current but when end-winding cooling is applied, it can be noted that the temperature drops to $130^{\circ} \mathrm{C}$ (i.e. about $25 \%$ temperature reduction). A second measurement (for validation reasons) obtained through a thermal camera confirms the validity of the thermocouple measurements. Fig. 9 shows the thermographic results, with and without direct cooling of the end-windings, at $41 A$ DC current.

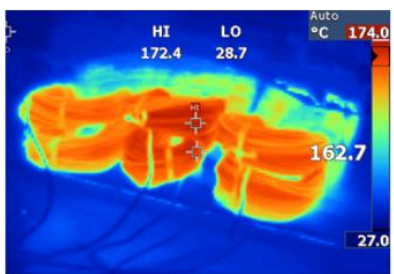

Traditional Cooling

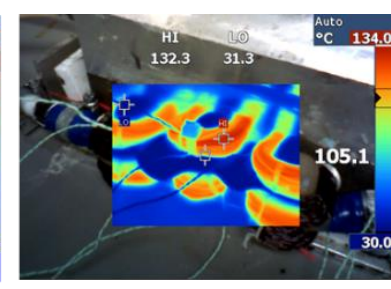

Proposed Cooling
Fig. 9. End-winding thermography at $41 A$ DC current.

All the above confirms that the PCM not only drastically reduces the end-windings temperature, but it also lowers the temperature inside the slot, by promoting the heat transfer along the axial direction. To point out the benefits of the proposed method, TABLE II highlights the cooling improvement $\Delta \theta$, for both slot and end-windings temperatures. 
TABLE II

Traditional (T) VS. Proposed (P) METHODS - TeMPERATURE IMPROVEMENT

\begin{tabular}{cccccccc}
\hline \hline $\begin{array}{c}\mathbf{I}_{\mathbf{D C}} \\
{[\mathbf{A}]}\end{array}$ & $\begin{array}{c}\mathbf{J} \\
{\left[\mathbf{A} / \mathbf{m m}^{2}\right]}\end{array}$ & $\begin{array}{c}\boldsymbol{\theta}_{\mathbf{s}} \mathbf{T} \\
{\left[{ }^{\circ} \mathbf{C}\right]}\end{array}$ & $\begin{array}{c}\boldsymbol{\theta}_{\mathbf{s}} \mathbf{P} \\
{\left[{ }^{\circ} \mathbf{C}\right]}\end{array}$ & $\begin{array}{c}\Delta \boldsymbol{\theta}_{\mathbf{s}} \\
{[\boldsymbol{\%}]}\end{array}$ & $\begin{array}{c}\boldsymbol{\theta}_{\text {ew }} \mathbf{T} \\
{\left[{ }^{\circ} \mathbf{C}\right]}\end{array}$ & $\begin{array}{c}\boldsymbol{\theta}_{\text {ew }} \mathbf{P} \\
{\left[{ }^{\circ} \mathbf{C}\right]}\end{array}$ & $\begin{array}{c}\Delta \boldsymbol{\theta}_{\text {ew }} \\
{[\boldsymbol{\%}]}\end{array}$ \\
\hline 20 & 5.0 & 46.4 & 41.4 & -10.9 & 56.7 & 47.8 & -15.7 \\
25 & 6.4 & 59.1 & 50.3 & -14.8 & 74.9 & 60.2 & -19.7 \\
30 & 7.6 & 74.3 & 60.5 & -18.7 & 96.9 & 74.9 & -22.7 \\
35 & 8.9 & 95.4 & 75.2 & -21.2 & 126.1 & 94.6 & -25.0 \\
37.5 & 9.5 & 109.0 & 85.7 & -21.4 & 144.1 & 107.8 & -25.2 \\
40 & 10.2 & 124.8 & 96.8 & -22.4 & 163.6 & 122.5 & -25.1 \\
41 & 10.4 & 132.2 & 102.3 & -22.6 & 172.4 & 129.7 & -24.8 \\
\hline \hline
\end{tabular}

Despite the longer end-windings, necessary for accommodating the PCM, the overall winding temperature reduction results in lower winding electrical resistance. This leads to a decrease in Joule losses for DC current higher than $30 \mathrm{~A}$ (i.e. $J>7.6 \mathrm{~A} / \mathrm{mm}^{2}$ ), as reported in TABLE III. The Joule losses $P_{j}$ are measured for several configurations, such as 1) water jacket cooling and original length (1 p.u.) end-windings $\left.\left(P_{j} T\right), 2\right)$ water jacket cooling and elongated (2.66 p.u.) endwindings $\left(P_{j} T-E\right)$, and 3$) \mathrm{PCM}\left(P_{j} P\right)$. The obtained results are listed in TABLE III, along with the losses reduction $(\triangle P j=$ $\left.P_{j} P-P_{j} T\right)$ for several DC current $I_{D C}$ values. When the winding is supplied with $41 A$ DC current, $3.7 \%$ Joule losses reduction is achieved by directly cooling the end-windings.

It is worth to remark that the main purpose of the PCM is to reduce the hot-spot temperature in order to allow higher current and torque densities. This can result either in a higher torque using the same stator geometry (if the iron path is not saturated), or in a shorter machine capable to develop the same rated torque.

Elongating and splitting the end-windings for fitting the cooling pipe did not affect the slot fill factor. In fact, a key constraint during the dummy stator winding process was to maintain the fill factor equal to 0.45 (i.e. value for the existing electrical machine), for a fair comparison. The relative low value of the used fill factor is mainly due to the adoption of random-wound round enamelled conductors for the windings. Nevertheless, a higher fill factor can be reached in singlelayer concentrated windings by adopting rectangular conductors and/or preformed coils [27]. It is noteworthy underline that the fill factor value does not compromise the feasibility of the PCM.

TABLE III

Traditional (T) vs. Proposed (P) Methods - Joule Losses IMProvement

\begin{tabular}{cccccc}
\hline \hline $\mathbf{I}_{\mathbf{D C}}[\mathbf{A}]$ & $\mathbf{P}_{\mathbf{j}} \mathbf{T}[\mathbf{W}]$ & $\mathbf{P}_{\mathbf{j}} \mathbf{T}-\mathbf{E}[\mathbf{W}]$ & $\mathbf{P}_{\mathbf{j}} \mathbf{P}[\mathbf{W}]$ & $\mathbf{\Delta}_{\mathbf{j}}[\mathbf{W}]$ & $\mathbf{\Delta P}_{\mathbf{j}}[\boldsymbol{\%}]$ \\
\hline 20 & 60.5 & 63.0 & 62.0 & 1.5 & 2.5 \\
25 & 100.4 & 104.5 & 101.3 & 0.9 & 0.9 \\
30 & 154.2 & 160.5 & 152.7 & -1.5 & -0.9 \\
35 & 225.7 & 234.9 & 220.5 & -5.2 & -2.3 \\
37.5 & 273.5 & 284.6 & 265.1 & -8.4 & -3.1 \\
40 & 327.9 & 341.2 & 316.0 & -11.9 & -3.6 \\
41 & 349.1 & 363.3 & 336.2 & -12.9 & -3.7 \\
\hline \hline
\end{tabular}

Due to the choice of insulation class, the original traction machine was thermally designed for a $180^{\circ} \mathrm{C}$ limitation resulting in a current density of $10.4 \mathrm{~A} / \mathrm{mm}^{2}$ (with water jacket cooling only). However, the results obtained when end-winding cooling is applied, imply that a higher current density $\left(\approx 12.2 \mathrm{~A} / \mathrm{mm}^{2}\right)$ can be used without any risk of overheating the winding insulation. On the other hand, it can also be argued that if the original current density is kept and end-winding cooling implemented, then the resulting thermal improvement would bring a considerable extension of insulation lifetime, as the latter is related to the hot-spot temperature through an exponential law [33]. It is important to note that the results presented in this section refer to the case where the proposed method is applied only to one end-windings side. Hence, further improvements, in terms of temperature and Joule losses reductions, are expected when both end-windings sides are directly cooled, as illustrated in Fig. 10. Considering Fig. 10, the overall flow rate available (i.e. $10 \mathrm{~L} / \mathrm{min}$ ) is split between the housing water jacket (i.e. $6 \mathrm{~L} / \mathrm{min}$ ) and the two end-windings sides (i.e. $2 \mathrm{~L} / \mathrm{min}$ each) by using a flow regulator.

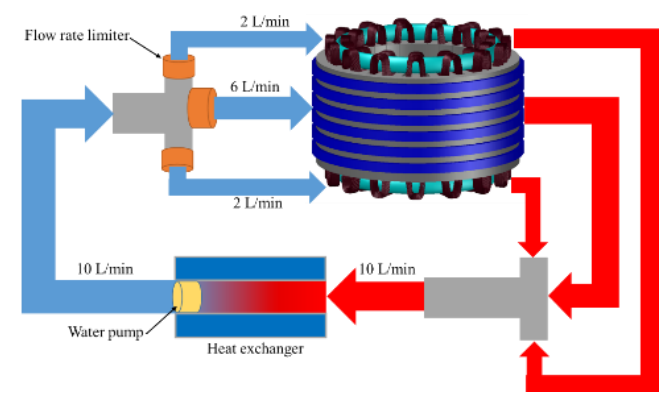

Fig. 10. Hydraulic circuit for cooling both end-windings sides using the PCM.

\section{LUMPED PARAMETERS THERMAL NETWORKS}

Having confirmed the adequateness of the proposed methodology, then the next step is to perform a quantitative analysis of the pipe materials. An appropriate tool for predicting slot and end-windings temperatures is thus required. In this work, a particular LPTN methodology was chosen. The rationale behind this choice is that experimental results (from the motorettes) were available, and therefore the historical weakness of LPTNs, related to accurate definitions of parameters such as the convection coefficients, can be easily mitigated through these experimental results. This of course means that no computationally-heavy numerical systems such as Computational Fluid Dynamics (CFD), and Finite-Elements (FE) need to be used.

\section{A. Highly-discretised LPTN}

In the first instance, a highly-discretised LPTN (i.e. 78-nodes) is developed for ensuring accuracy at the expense of computational speed. The LPTN consists of heat sources, temperature sources, thermal resistances and capacitances, which are connected to thermal nodes. Due to the motorette symmetry, only one slot and one tooth are modelled, as shown in Fig. 11, where the conceptual blueprint of the highly-discretised LPTN is depicted. For the sake of clarity, not all the 78-nodes are represented in Fig. 11. For instance, the drawing reports one node inside slot section, while in reality 4 nodes are actually implemented for each slot section.

The LPTN of Fig. 11 considers only radial and tangential heat transfers (i.e. axial heat transfer is neglected). However, the previously presented experimental findings, prove the influence of the PCM on axial heat transfer. For this reason, a multi-slice approach is implemented, thus, the motorette is axially segmented in $n$ slices interconnected through axial resistances $R_{a x}$, as schematically reported in Fig. 12, where an example of a two slices LPTN is depicted. The interconnection between slices is modelled by using only axial resistances at the slot section. This assumption is valid since the core thermal conductivity is two orders of magnitude lower than that of the winding. The implemented highlydiscretised LPTN employs 3 axial slices and 2 axial resistances. 


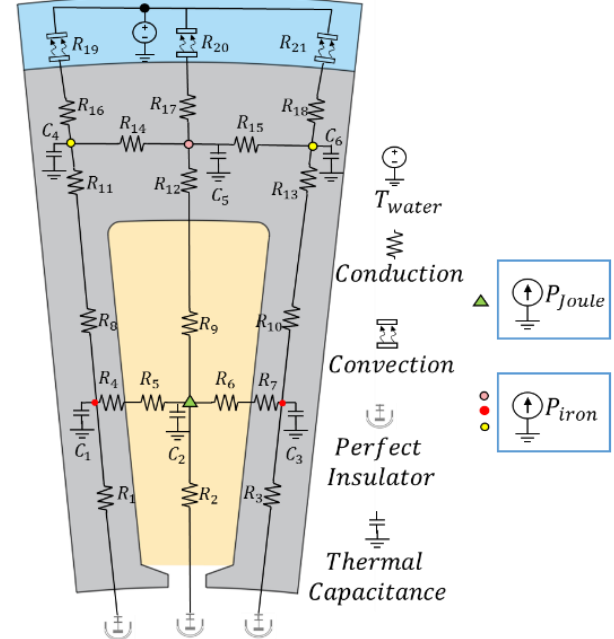

Fig. 11. Conceptual blueprint of the highly-discretised LPTN.

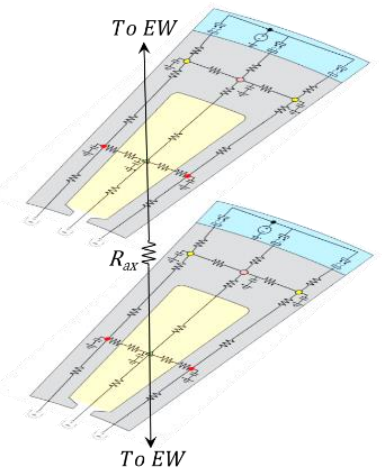

Fig. 12. Example of two-slices axially segmented LPTN.

Adopting the approach reported in [34], the end-winding volume is discretised into 24 cubic-shaped thermal units, as shown in Fig. 133. Each thermal unit takes into account 3D heat transfer (i.e. axial, radial and tangential) and it consists of 6 thermal resistances and 1 heat source. The Joule losses provided by the heat source are proportional to the copper volume. This modelling strategy allows precise temperature estimation in the end-winding, but its computation time increases linearly with the number of thermal units.

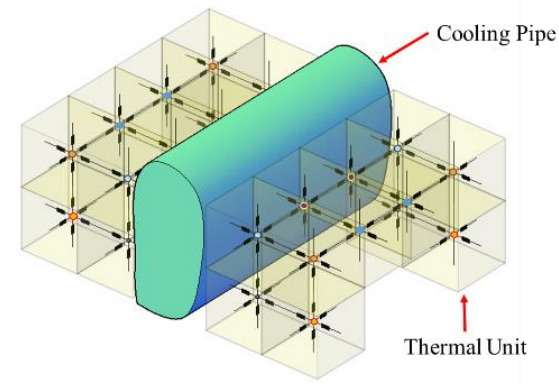

Fig. 13. End-windings model adopted for highly-discretised LPTN.

An example of a 6-nodes thermal network modelling the end-windings is given in Fig. 14. This visualizes the connection between the end-windings thermal network and the rest of the LPTN. The end-winding nodes are connected axially to the slot nodes and radially to the cooling pipe. The resistances between the end-windings nodes and the cooling liquid account for 1) enamelled copper wires in the radial direction, 2) thermal interface between end-windings and pipe, 3) heat conduction through the pipe wall, 4) heat convection between pipe and cooling fluid and 5) heat convection between end-windings and surrounding air.

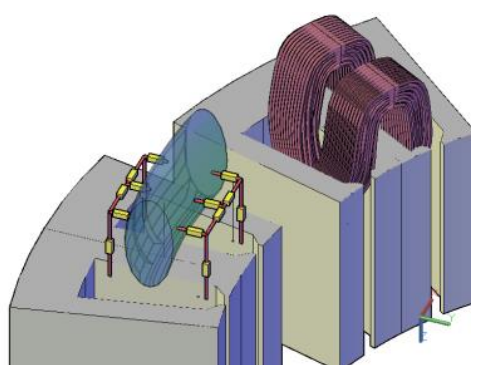

Fig. 14. Example of 6-nodes LPTN for end-windings modelling.

\section{B. Fine-tuning of the highly-discretised LPTN}

The described 78-nodes LPTN is implemented in Matlab Simscape $^{\mathrm{TM}}$, and Simulink Design Optimization ${ }^{\mathrm{TM}}$ is used for its fine-tuning. The measured temperature profiles, for various DC currents are imported into the platform and the critical parameters are estimated using the Sequential Quadratic Programming (SQP) algorithm [35]. These include

- the natural air convection coefficient $h_{\text {air }}$

- the cooling pipe forced convection coefficient $h_{p i p e}$

- the water jacket forced convection coefficient $h_{w j}$

- the slot equivalent thermal conductivity $k_{\text {rad }}$

For these critical parameters, the possible range of variation is defined in literature $[18,36]$. For facilitating the tuning procedure, the variation range of $h_{w j}$ has been also predicted analytically through the dimensionless analysis (i.e. using Nusselt, Prandlt and Reynolds numbers). Regarding the end-winding cooling pipe, it is very difficult to analytically derive the convection coefficient, because of the irregular pipe geometry (i.e. variable cross sectional area along the pipe's length). In fact, the expansion of the cooling pipe leads to significant turbulence in the liquid flow, which cannot be accurately modelled without CFD analysis (a future goal). However, the cooling flow turbulence was taken into account when calibrating the heat transfer coefficient of the pipe by considering hot-spot temperature of the end-winding. To account for any discrepancy in the modelled temperature distribution, the worst case scenario due to this uneven flow is already accounted for.

The variation ranges of critical parameters are provided as input to the SQP algorithm, in order to limit the search space and reduce the convergence time. The aim of the SQP algorithm is to minimise the objective function, which is defined as the error between the measured temperature and the one predicted by the highly-discretised LPTN. In TABLE IV, the estimated critical parameters together with their variation range are reported.

TABLE IV

ESTIMATED CRITICAL PARAMETERS AND THEIR RANGE OF VARIATION [18, 36]

\begin{tabular}{ccc}
\hline \hline Parameter & Estimated Value & Variation Range \\
\hline$h_{\text {air }}\left[\mathrm{W} / \mathrm{m}^{2} / \mathrm{K}\right]$ & 4.00 & $2-20$ \\
$h_{\text {pipe }}\left[\mathrm{W} / \mathrm{m}^{2} / \mathrm{K}\right]$ & 337 & $100-2500$ \\
$h_{w j}\left[\mathrm{~W} / \mathrm{m}^{2} / \mathrm{K}\right]$ & 1250 & $100-2500$ \\
$k_{\text {rad }}[\mathrm{W} / \mathrm{m} / \mathrm{K}]$ & 1.20 & $0.5-2$ \\
\hline \hline
\end{tabular}

Thermal parameters, such as lamination, housing and slot liner thermal conductivities, are chosen from literature, according to the material $[18,36]$. For each thermal unit (i.e. cuboid), the contact resistance between pipe and end-windings surfaces is modelled as equivalent air gap (2), where $t_{\text {int }}$ is the gap interface thickness, $k_{\text {air } 90}$ is the air thermal conductivity at $90^{\circ} \mathrm{C}$ and $A_{c u b}$ is the contact surface area between pipe and end-windings for each thermal unit. 


$$
R_{\text {con }}=\frac{t_{\text {int }}}{k_{\text {air } 90} A_{\text {cub }}}
$$

The air conductivity at $90^{\circ} \mathrm{C}$ is selected, because an average end-windings temperature of $90^{\circ} \mathrm{C}$ was recorded during the tests at several DC current values. The air layer thickness ranges from $0.01 \mathrm{~mm}$ to $0.1 \mathrm{~mm}$, depending on the fitting between pipe and end-windings surfaces, in each thermal unit.

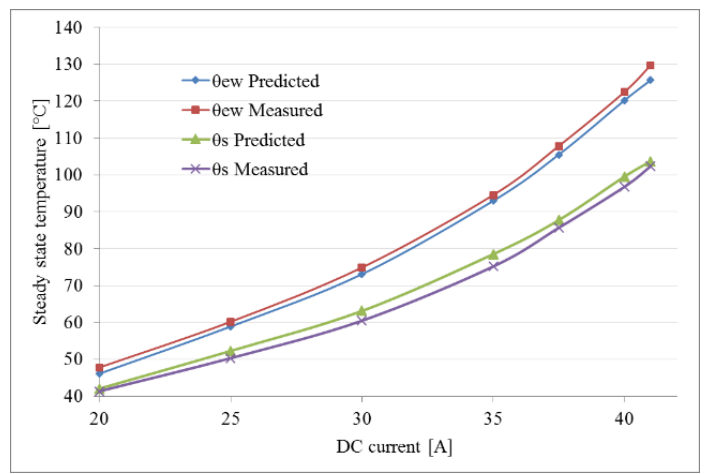

Fig. 15. Highly-discretised LPTN - Measured vs. predicted temperatures.

To facilitate the tuning procedure, the thermal capacitances are neglected and therefore the highly-discretised LPTN only predicts the steady-state temperatures. A series of tests with DC currents ranging from $20 \mathrm{~A}$ to $41 \mathrm{~A}$ were then conducted. Fig. 15 compares the measured results with the predicted steady-state temperatures for these various currents. It can be easily observed that the difference between the measured and the predicted temperatures is within a relative error of $5 \%$.

\section{Reduced node LPTN}

Although, the highly-discretized LPTN (i.e. 78-nodes LPTN) provides an accurate temperature estimation, it requires considerable computational time and resources, due to its complexity. The presence of 24 thermal units on the end-windings region, means that the fine-tuning of the LPTN with these many nodes is time consuming.

Recent literature has shown that reduced node LPTNs can achieve the same accuracy level of more complex LPTNs [35]. On this basis, a sensitivity analysis is performed on the highly-discretized LPTN, with the aim of reducing the number of nodes. A simplified LPTN decreases the computational time and facilitates the tuning process, enabling thermal transient behaviour modelling by including thermal capacitances [35]. As previously mentioned, this feature is not strictly necessary for performing the quantitative analysis of the pipe materials to be used in the PCM, but it is essential for short-time duty-cycles electrical machines. Hence, once the reduced node LPTN is built, the performance of the PCM can also be evaluated during transient conditions.

The findings from both the LPTN and experimental tests confirm that the slot temperature is lower than the end-windings temperature. Therefore, the axial heat transfer is not negligible when direct cooling is applied to the end-windings. For this reason, the reduced node LPTN must model axial heat transfer, as well as, radial and tangential.

A sensitivity analysis exercise based on finding the number of nodes that results in an optimum between accuracy and use of computational resources is carried out. This analysis was performed by following the steps listed below:
1. Initially the machine's temperature is estimated using the 78-nodes LPTN;

2. The isothermal nodes (i.e. nodes at the same temperature that is $+/-3^{\circ} \mathrm{C}$ ) are merged (nodes with same colour in Figs. 11, 12 and 13);

3. Only the nodes representative of hot-spot temperatures are kept for each machine's portion;

4. Equivalent resistances are determined by series/parallel computation.

The sensitivity analysis outcome is shown in Fig. 16, where an equivalent 7-nodes LPTN is depicted. The thermal resistances and capacitances adopted in the 7-nodes LPTN are described in TABLE V.

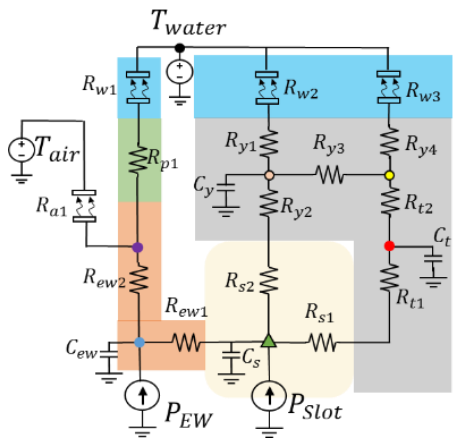

Fig. 16. The resulting 7-nodes LPTN.

The nodes accounting for the hot-spot within the active length of the machine (i.e. slot) and the end-windings are kept in the 7-nodes LPTN. Furthermore, three nodes are used for modelling the stator core, namely one in the tooth and two in the back iron. The remaining two nodes are the interconnection between the temperature sources (i.e. cooling water and natural air respectively). A colour code is used for helping the reader in identifying the nodes in the various LPTNs (see Fig. 11, 12 and 13).

TABLE V

THERMAL RESISTANCES (R) AND CAPACITANCES (C) USED IN THE 7-NODES LPTN

\begin{tabular}{|c|c|}
\hline Component & Description \\
\hline$R_{s 1}$ & Tangential slot \\
\hline$R_{s 2}$ & Radial slot \\
\hline$R_{y 3}$ & Tangential yoke \\
\hline$R_{y 1}, R_{y 2}, R_{y 4}$ & Radial yoke \\
\hline$R_{t 1}, R_{t 2}$ & Radial tooth \\
\hline$R_{p 1}$ & Pipe + Contact pipe / end-windings \\
\hline$R_{e w 1}, R_{e w 2}$ & End-windings \\
\hline$R_{w 1}$ & Pipe / Cooling fluid convection \\
\hline$R_{w 2}, R_{w 3}$ & Water jacket / stator convection \\
\hline$R_{a 1}$ & Convection end-windings / air \\
\hline$C_{s}$ & Slot \\
\hline$C_{y}$ & Yoke \\
\hline$C_{t}$ & Tooth \\
\hline$C_{e w}$ & End-windings \\
\hline
\end{tabular}

Due to the nature of the end-windings geometry, care must be taken when determining the values of $R_{e w 1}, R_{e w 2}, R_{p 1}$, and $R_{a l}$. The end-windings geometry is considered as single thermal unit, having uniform equivalent thermal conductivity (i.e. accounting for copper, insulation and air).

The end-windings thermal dimensions are shown in Fig. 17 , where $T w$ is the tooth width, $S w$ is the slot average width, $S d$ is the slot depth and EWext is the end-windings extension. Except for EWext, the mentioned dimensions are linked to the motorette core geometry. Hence, the presented 7-nodes LPTN is tailored on the motorette used during the experimental tests. 


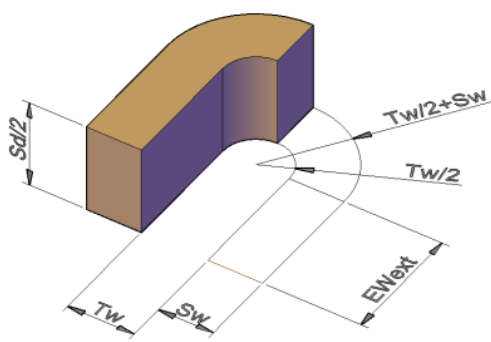

Fig. 17. Split end-windings geometry used as thermal unit.

However, this does not affect the general validity of the used approach, since knowing the slot geometry and the endwindings length of any electrical machine, a new reduced node LPTN can be built. The end-winding thermal resistances $R_{e w 1}, R_{e w 2}$ are calculated by using (3), where $l_{e w}$ is the endwindings average length and $k_{e w}$ is the equivalent endwindings thermal conductivity.

$$
R_{e w 1}=R_{e w 2}=\frac{0.5 l_{e w}}{S w \cdot S d \cdot k_{e w}}
$$

The pipe thermal resistance $R_{p l}$, that includes the contact resistance between cooling pipe and end-windings, is obtained from (4), where the available cooling area of the end-windings $A_{e w}$ also used for determining $c f$, is given by (5). The area $A_{e w}$ is the sum of 4 sub-areas (i.e. $b 1, b 2, b 3$ and $b 4$ ). These areas are highlighted in Fig. 18.

$$
\begin{gathered}
R_{p 1}=\frac{t_{\text {pipe }}}{A_{\text {ew }} \cdot k_{\text {pipe }} \cdot c f} \\
A_{\text {ew }}=b 1+b 2+b 3+b 4 \\
b 1=S w \cdot 2 E W \text { ext } \\
b 2=0.5 \pi\left[(0.5 T w+S w)^{2}-(0.5 T w)^{2}\right] \\
b 3=0.5(S d \cdot \pi \cdot T w) \\
b 4=0.5 S d \cdot E W \text { ext }
\end{gathered}
$$

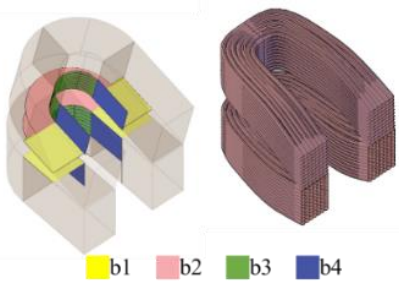

Fig. 18. End-windings sub-areas selected to compute $A_{e w}$.

The 7-nodes LPTN uses 2 heat sources, namely $P_{\text {slot }}$ and $P_{e w}$ which model slot and end-windings Joule losses respectively. These are calculated by (6) and (7), where $n_{t}$ is the number of turns, $L$ is the stack length, $S_{\text {cond }}$ is the conductor cross-section area, $I_{D C}$ is the current flowing through the conductor and $\rho(\theta)$ is the copper resistivity at temperature $\theta$.

$$
\begin{gathered}
\text { Pslot }=\frac{n_{t} \cdot L \cdot \rho\left(\theta_{S}\right)}{S_{\text {cond }}} \cdot I_{D C}{ }^{2} \\
\text { Pew }=\frac{n_{t} \cdot l_{\text {ew }} \cdot \rho\left(\theta_{\text {ew }}\right)}{S_{\text {cond }}} \cdot I_{D C}{ }^{2}
\end{gathered}
$$

The resistivity value is automatically updated at each simulation instant, based on the estimated temperatures (i.e. $\theta_{s}$ and $\left.\theta_{e w}\right)$. The LPTN includes also 2 temperature sources, namely $T_{\text {water }}$ and $T_{\text {air }}$, whose magnitudes are defined by the experimentally recorded temperatures of cooling fluid (i.e. water) and air respectively. The effects of the ambient temperature have been seen to have a very minor influence when the cooling pipe is applied. Although the experimental set-up has two separated hydraulic circuits for water jacket and cooling pipe, the measured water temperature at both chillers' outlet was identical. This justifies the presence of a single water temperature-source in the 7-nodes LPTN.

\section{Fine-tuning and comparisons of the reduced node LPTN}

Following the procedure explained in Part B of Section V, the 7-nodes LPTN is fine-tuned by the same software platforms. Based on the measured temperatures, the thermal capacitances of the slot $C_{\text {slot }}$, end-windings $C_{e w}$, yoke $C_{\text {yoke }}$ and tooth $C_{\text {tooth }}$, alongside with the equivalent end-windings thermal conductivity $k_{e w}$ are estimated. The values obtained by using the SQP algorithm are summarized in TABLE VI. During the fine-tuning procedure, the convection coefficients for natural air $h_{a i r}$, cooling pipe $h_{\text {pipe }}$ and water jacke $h_{w j}$ are kept equal to the values previously estimated and listed in TABLE IV. The same applies to the slot equivalent thermal conductivity $k_{\text {rad }}$.

TABLE VI

\begin{tabular}{cc}
\hline ESTIMATED THERMAL PARAMETERS FOR 7-NODES LPTN \\
\hline Thermal parameter & Estimated value \\
\hline$k_{\text {ew }}$ & $61.2 \mathrm{~W} / \mathrm{m} / \mathrm{K}$ \\
$C_{e w}$ & $30.5 \mathrm{~J} / \mathrm{K}$ \\
$C_{\text {slot }}$ & $74.1 \mathrm{~J} / \mathrm{K}$ \\
$C_{\text {tooth }}$ & $141.2 \mathrm{~J} / \mathrm{K}$ \\
$C_{\text {yoke }}$ & $136.1 \mathrm{~J} / \mathrm{K}$ \\
\hline
\end{tabular}

The fine-tuned 7-nodes LPTN is then used to predict the slot and end-windings temperature profiles (i.e. transient temperatures). Fig. 19 compares the predicted and measured temperature profiles for both slot and end-windings, when a DC current of $40 A$ flows through the winding. The relative error between measured and predicted temperatures is small. In fact, its value is below $3.5 \%$ for the whole time window considered (i.e. from $0 s$ to $1000 s$ ).

To assess the accuracy of the reduced node LPTN, its predicted winding temperatures (i.e. slot and end-windings) at steady-state are compared with the ones predicted by the 78nodes LPTN and the measured temperatures. This comparison is repeated for several DC current values and the obtained results are reported in Fig. 20.

Considering the steady-state end-windings temperatures, both the predicted results (i.e. 7-nodes and 78-nodes LPTNs) are slightly lower than the measured one. Conversely, the LPTNs tends to moderately overestimate the steady-state slot temperature. However, the difference between predicted and measured temperatures is reasonable, for both slot and end-windings. Comparing the predicted temperatures, the 7-nodes LPTN results reveal a negligible discrepancy with respect to the results of the more complex 78-nodes LPTN.

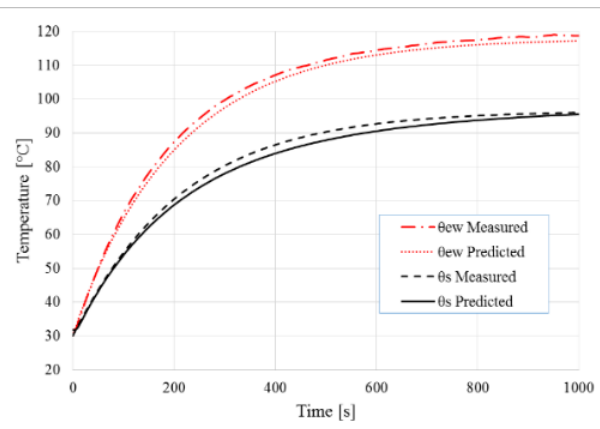

Fig. 19. Measured vs. predicted temperature profiles at $40 \mathrm{~A}$ using the 7-nodes LPTN. 


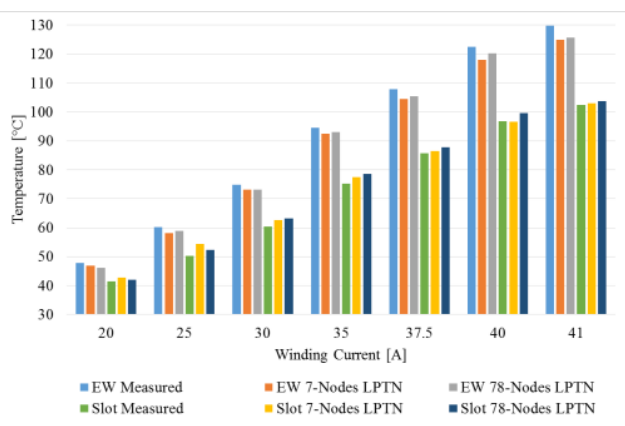

Fig. 20. LPTNs vs measured temperature comparison.

Once the accuracy of both the LPTNs has been verified, their computational time performances are evaluated. When using Matlab $\mathrm{r} 2016 \AA$ installed on a computer equipped with an Intel ${ }^{\circledR}$ Xeon ${ }^{\circledR}$ E5-1620 $3.50 \mathrm{GHz}$ CPU with $32 G B$ of RAM, the time required for a steady-state simulation is measured. The obtained results are presented in TABLE VII, where it can be observed that the 7-nodes LPTN is more than 16 times faster. For sake of completeness, TABLE VII also considers the time required during the fine-tuning process by both LPTNs. As expected, the 7-nodes LPTN proved once again its effectiveness over the 78-nodes LPTN.

The described LPTNs can be employed for redesigning the machine accounting for the enhanced cooling resulting from the application of the PCM. The machine redesign will be addressed in a separate publication, where the experimentally validated 7-node LPTN will be used for further machine optimisation. The presented analysis has given significant confidence in the 7-node LPTN and although the time differences may seem small, over 1000 optimization designs this would be more than 5 hours saved. In addition, given the short computational time of the 7-nodes LPTN, it can be adopted for online temperature estimation of the machine and for insulation lifetime prediction models.

TABLE VII

COMPUTATIONAL Times FOR LPTNS SimULATION AND Fine TUNING

\begin{tabular}{ccc}
\hline \hline Model & $\begin{array}{c}\text { Simulation time } \\
\text { (steady-state) }\end{array}$ & $\begin{array}{c}\text { Simulation time } \\
\text { (transient) }\end{array}$ \\
\hline 78 -node & $21.70 \mathrm{~s}$ & - \\
7 -node & $1.31 \mathrm{~s}$ & $2.71 \mathrm{~s}$ \\
\hline \hline Model & $\begin{array}{c}\text { Iterations for SQP } \\
\text { algorithm to } \\
\text { converge }\end{array}$ & $\begin{array}{c}\text { Elapsed time } \\
\text { before } \\
\text { convergence }\end{array}$ \\
\hline 78 -node & 37 & $48 \mathrm{~m} 24 \mathrm{~s}$ \\
7 -node & 16 & $8 \mathrm{~m} 31 \mathrm{~s}$ \\
\hline \hline
\end{tabular}

\section{QUANTITATIVE ANALYSIS OF THE PIPE MATERIALS}

According to the qualitative trade-off study (i.e. based only on the materials thermo-mechanical properties) introduced in Section III, the most suitable material for the cooling pipe was the silicone rubber. Therefore, silicone rubber pipe was used for equipping the motorette adopted during the experimental tests. In order to validate the claim made in Section III, the fine-tuned 7-nodes LPTN is then employed to analyse how the whole system performs if the different pipe materials of TABLE I are utilised. The results obtained from this quantitative analysis are given for both steady-state and transient performance.

The steady-state performance of the PCM are appraised by considering a DC current of $40 \mathrm{~A}$ flowing through the winding. The predicted end-windings temperatures, for each considered material, are listed in TABLE VIII, together with the absolute and relative temperature reductions.
TABLE VIII

Steady-State Performance for Different Cooling PiPe Materials (at 40A)

\begin{tabular}{cccc}
\hline \hline Material & $\boldsymbol{\theta}_{\mathrm{ew}}\left[{ }^{\circ} \mathbf{C}\right]$ & $\boldsymbol{\theta}_{\mathrm{ew}}$ Reduction $\left[{ }^{\circ} \mathbf{C}\right]$ & $\boldsymbol{\theta}_{\mathrm{ew}}$ Reduction [\%] \\
\hline PVC & 159.2 & -4.8 & -2.9 \\
ABS & 160.0 & -4.0 & -2.4 \\
PTFE & 154.6 & -9.4 & -5.7 \\
Sil. Rubber & 118.0 & -46.0 & -28.1 \\
Nylon & 157.2 & -6.8 & -4.2 \\
Copper sq. & 141.9 & -22.1 & -13.5 \\
Copper ro. & 149.1 & -14.9 & -9.1 \\
Stainl. St. & 149.2 & -14.8 & -9.0 \\
Aluminium & 149.1 & -14.9 & -9.1 \\
Ceramic & 149.4 & -14.6 & -8.9 \\
Glass & 155.9 & -8.1 & -4.9 \\
Carb. Fib. & 149.8 & -14.2 & -8.7 \\
\hline \hline
\end{tabular}

The contact factor values used for this trade-off analysis are the ones reported in TABLE I.

The temperature reductions are determined with respect to $164^{\circ} \mathrm{C}$, which is the steady-state end-windings temperature, when $40 \mathrm{~A}$ DC current is applied and the end-windings are not directly cooled. Analysing the steady-state results, the only pipe materials, which provides a double-digit relative temperature reduction, are silicone rubber (i.e. $-28 \%$ ) and the square-shaped copper (-13.5\%). While this last one has an interesting result (even if not as good as the chosen silicone), from a practical perspective, this option is unacceptable. In fact, such a metal pipe comes with the risk of shorts across terminals and coils. At the same time, the variable magnetic fields in the end-winding region can induce AC eddy current in the metallic pipe, causing overheating by Joule effect.

Finally, the transient performance of the PCM is assessed, considering a $40 \mathrm{~A}$ DC current. The obtained results are depicted in Fig. 21, where for clarity, only the temperature profiles of four materials are shown. The quantitative analysis results confirm the outcome provided by the qualitative tradeoff study. Therefore, the silicone rubber pipe is strongly recommended for maximizing the cooling performance of the PCM.

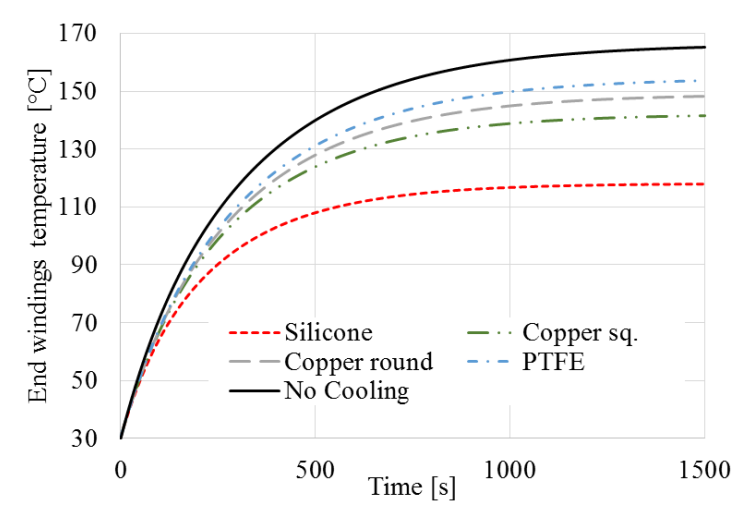

Fig. 21. Predicted end-windings temperatures at $40 \mathrm{~A}$ comparing differen materials.

\section{APPLICATION OF THE PCM}

The PCM was designed for an automotive traction application where high torque density and a wide efficiency range was required, for meeting the FreedomCar 2020 targets [36]. Using traditional cooling methods two $30 \mathrm{~kW}$ machines were designed for these objectives. An internal permanent magnet machine (IPM), which could achieve the torque density but not the high speed efficiency. The other, a permanent magnet assisted synchronous reluctance machine (PMa-SynRelM), while it could achieve the efficiency targets, would overheat when attempting to develop the peak torque. 
The PCM allowed the PMa-SynRelM, to push to higher currents, reaching the desired torque-speed requirement, while enhancing the efficiency to meet the $95 \%$ constraint. Further, the adoption of the PCM led to the hot-spot temperature reduction for low speed operations (i.e. up to the base speed). In fact, the maximum continuous current density improved from $10 \mathrm{~A} / \mathrm{mm}^{2}$ (water jacket cooling only) to $12 \mathrm{~A} / \mathrm{mm}^{2}$ (water jacket + PCM). Despite the $20 \%$ increment of current density, the torque at base speed raised by only $18 \%$ because of the iron magnetic saturation. For operations at high speed (i.e. flux weakening region), the PMa-SynRelM performance is not influenced by the PCM, since the main constraint is the DC link voltage.

Finally, a cost analysis has performed in order to evaluate the cost increment due to the application of the PCM. Considering the liquid cooled PMa-SynRelM, the cost of the PCM represent the $2 \%$ of the overall machine cost. Such additional cost is mainly related to the required modifications on the hydraulic circuit (i.e. installation of flow rate limiters), since the pipe itself costs less than $\$ 15$ per linear meter. The slightly higher cost of the machine equipped with the PCM is exceeded by the indisputable benefits in terms of thermal management and current density improvements.

\section{CONCLUSIONS}

The PCM results in a significant reduction of winding temperatures (both for end-windings and slot), by simply directly cooling the end-windings. Its effectiveness was experimentally proven and a $25 \%$ end-winding temperature reduction was achieved, even if the cooling method was applied to one end-windings side only. Further thermal improvements are expected when the direct cooling is applied on both end-windings sides. The PCM is not expensive relatively to the overall machine cost and can be applied to many topologies of electrical machines.

Apart from introducing a novel thermal management method, the paper provides the detailed procedure for building and fine-tuning a highly-discretised LPTN (i.e. 78-nodes LPTN), as well as a reduced node LPTN (i.e. 7-nodes LPTN). The LPTNs performances are evaluated in terms of both prediction accuracy and computational time. In particular, it is shown that the reduced node LPTN decreases the simulation time from $21.7 \mathrm{~s}$ to $1.31 \mathrm{~s}$, without significantly compromising the prediction accuracy.

Finally, several pipe materials, including metals, polymers, composites and ceramics are investigated, in order to select the most suitable. Both qualitative and quantitative analyses on pipe materials identify silicone rubber pipe as the best choice for enhancing the cooling capability of the PCM. This is mainly due to the expansion of silicone rubber pipe, when carrying pressurised fluid.

\section{REFERENCES}

[1] Z. A. Needell, J. McNerney, M. T. Chang, and J. E. Trancik, "Potentia for widespread electrification of personal vehicle travel in the United States," Nature Energy, vol. 1, p. 16112, 2016.

[2] Airbus, "Future Energy Sources," Available: http://www.aircraft.airbus.com/innovation/future-by-airbus/futureenergy-sources/Accessed: Dec. 2017.

[3] V. Madonna, P. Giangrande, and M. Galea, "Electrical Power Generation in Aircraft: review, challenges and opportunities," in press on IEEE Transactions on Transportation Electrification, 2018, DOI: 10.1109/TTE.2018.2834142

[4] M. Galea, C. Gerada, T. Raminosoa, and P. Wheeler, "A Thermal Improvement Technique for the Phase Windings of Electrical Machines," IEEE Transactons on Industrial Applications, vol. 48, pp. 79-87, 2012.
[5] S. Grubic, J. M. Aller, B. Lu, and T. G. Habetler, "A Survey on Testing and Monitoring Methods for Stator Insulation Systems of LowVoltage Induction Machines Focusing on Turn Insulation Problems," IEEE Trans. on Ind. Electron., vol. 55, pp. 4127-4136, 2008.

[6] C. Sciascera, M. Galea, P. Giangrande, and C. Gerada, "Lifetime consumption and degradation analysis of the winding insulation of electrical machines," in 8th IET International Conference on Power Electronics, Machines and Drives (PEMD 2016), 2016, pp. 1-5.

[7] P. Arumugam, Z. Xu, A. L. Rocca, G. Vakil, M. Dickinson, E. Amankwah, et al., "High-Speed Solid Rotor Permanent Magnet Machines: Concept and Design," IEEE Transactions on Transportation Electrification, vol. 2, pp. 391-400, 2016.

[8] Z. Xu, A. L. Rocca, S. J. Pickering, C. Eastwick, C. Gerada, and S. Bozhko, "Mechanical and thermal design of an aeroengine starter/generator," in 2015 IEEE International Electric Machines \& Drives Conference (IEMDC), 2015, pp. 1607-1613.

[9] A. Al-Timimy, P. Giangrande, M. Degano, Z. Xu, M. Galea, C. Gerada, G. Lo Calzo, H. Zhang, L. Xia, "Design and Losses Analysis of a High Power Density Machine for Flooded Pump Applications," in IEEE Transaction On Industry Applications, vol. 54, no. 4, pp. 3260-3270, 2018.

[10] Z. Xu, C. Tighe, M. Galea, T. Hamiti, C. Gerada, and S. J. Pickering, "Thermal design of a permanent magnetic motor for direct drive wheel actuator," in 2014 International Conference on Electrical Machines (ICEM), 2014, pp. 2186-2192.

[11] Y. Yang, B. Bilgin, M. Kasprzak, S. Nalakath, H. Sadek, M. Preindl, et al., "Thermal management of electric machines," IET Electrical Systems in Transportation, vol. 7, pp. 104-116, 2017.

[12] L. Mingda, L. Yingjie, D. Hao, and B. Sarlioglu, "Thermal management and cooling of windings in electrical machines for electric vehicle and traction application," in 2017 IEEE Transp. Electrification Conference and Expo (ITEC), 2017, pp. 668-673.

[13] M. Popescu, D. A. Staton, A. Boglietti, A. Cavagnino, D. Hawkins, and J. Goss, "Modern Heat Extraction Systems for Power Traction Machines - A Review," IEEE Transactions on Industry Applications, vol. 52, pp. 2167-2175, 2016.

[14] M. Galea, C. Gerada, T. Raminosoa, P. Wheeler, , "Design of a high force density tubular permanent magnet motor," in The XIX Int. Conf. Elec. Mach.(ICEM'2010), Rome, Italy, 2010, pp. 1-6.

[15] B. Zhang, R. Qu, J. Wang, W. Xu, X. Fan, and Y. Chen, "Thermal Model of Totally Enclosed Water-Cooled Permanent-Magnet Synchronous Machines for Electric Vehicle Application," IEEE Trans. Ind. Applic., vol. 51, pp. 3020-3029, 2015.

[16] P. Lindh, M. G. Tehrani, T. Lindh, J. H. Montonen, J. Pyrhönen, J. T. Sopanen, et al., "Multidisciplinary Design of a Permanent-Magnet Traction Motor for a Hybrid Bus Taking the Load Cycle into Account," IEEE Trans. Ind. Electron., vol. 63, pp. 3397-3408, 2016.

[17] A. Al-Timimy, G. Vakil, M. Degano, P. Giangrande, C. Gerada, and M. Galea, "Considerations on the Effects that Core Material Machining has on an Electrical Machine Performance," in press on IEEE Transactions on Energy Conversion., DOI: 10.1109/TEC.2018.2808041.

[18] W. Tong, Mechanical Design of Electric Motors: Taylor \& Francis, 2014.

[19] A. M. E.-. Refaie, J. P. Alexander, S. Galioto, P. B. Reddy, K. K. Huh, P. d. Bock, et al., "Advanced High-Power-Density Interior Permanent Magnet Motor for Traction Applications," IEEE Trans. Ind. Appl., vol. 50, pp. 3235-3248, 2014.

[20] Z. Li, J. Guo, D. Fu, G. Gu, and B. Xiong, "Research on heat transfer of spraying evaporative cooling technique for large electrical machine," in ICEM'2009, proceedings of , 2009, pp. 1-4.

[21] M. Degano, P. Arumugam, W. Fernando, T. Yang, H. Zhang, J. B. Bartolo, et al., "An optimized bi-directional, wide speed range electric starter-generator for aerospace application," in 7th IET International Conference on Power Electronics, Machines and Drives (PEMD 2014), 2014, pp. 1-6.

[22] R. Camilleri, D. A. Howey, and M. D. McCulloch, "Predicting the Temperature and Flow Distribution in a Direct Oil-Cooled Electrical Machine With Segmented Stator," IEEE Transactions on Industrial Electronics, vol. 63, pp. 82-91, 2016.

[23] M. Visaria and I. Mudawar, "Application of Two-Phase Spray Cooling for Thermal Management of Electronic Devices," IEEE Trans. Comp. and Pack. Techn., vol. 32, pp. 784-793, 2009.

[24] S. Nategh, A. Krings, O. Wallmark, and M. Leksell, "Evaluation of Impregnation Materials for Thermal Management of Liquid-Cooled Electric Machines," IEEE Transactions on Industrial Electronics, vol. 61, pp. 5956-5965, 2014. 
[25] P. M. Lindh, I. Petrov, R. S. Semken, M. Niemelä, J. J. Pyrhönen, L. Aarniovuori, et al., "Direct Liquid Cooling in Low-Power Electrica Machines: Proof-of-Concept," IEEE Transactions on Energy Conversion, vol. 31, pp. 1257-1266, 2016.

[26] P. Lindh, I. Petrov, A. Jaatinen-Värri, A. Grönman, M. MartinezIturralde, M. Satrústegui, et al., "Direct Liquid Cooling Method Verified With an Axial-Flux Permanent-Magnet Traction Machine Prototype," IEEE Trans. on Ind. Electronics, vol. 64, pp. 6086-6095, 2017.

[27] M. Schiefer and M. Doppelbauer, "Indirect slot cooling for highpower-density machines with concentrated winding," in IEMDC'2015, 2015, pp. 1820-1825.

[28] D. Barater, F. Immovilli, A. Soldati, G. Buticchi, G. Franceschini, C. Gerada, M. Galea., "Multistress Characterization of Fault Mechanisms in Aerospace Electric Actuators," IEEE Transactions on Industrial Applications, vol. 53, pp. 1106-1115, 2017.

[29] J. Brandrup, E. H. Immergut, E. A. Grulke, A. Abe, and D. R. Bloch, Polymer handbook vol. 7: Wiley New York etc, 1989.

[30] W. D. Callister and D. G. Rethwisch, Materials science and engineering vol. 5: John Wiley \& Sons NY, 2011.

[31] A. Walker, M. Galea, C. Gerada, A. Mebarki, and D. Gerada, "Design considerations for high performance traction machines: Aiming for the FreedomCar 2020 targets," in 2015 International Conference on Electrical Systems for Aircraft, Railway, Ship Propulsion and Road Vehicles (ESARS), 2015, pp. 1-6.

[32] A. Walker, M. Galea, D. Gerada, C. Gerada, A. Mebarki, and N. Brown, "Development and design of a high performance traction machine for the FreedomCar 2020 traction machine targets," in 2016 XXII Int. Conf. on Elec. Mac. (ICEM), 2016, pp. 1611-1617.

[33] G. C. Stone, I. Culbert, E. A. Boulter, and H. Dhirani, Electrical Insulation for Rotating Machines: Design, Evaluation, Aging, Testing, and Repair: Wiley, 2014.

[34] R. Wrobel and P. H. Mellor, "A General Cuboidal Element for ThreeDimensional Thermal Modelling," IEEE Transactions on Magnetics, vol. 46, pp. 3197-3200, 2010.

[35] C. Sciascera, P. Giangrande, L. Papini, C. Gerada, and M. Galea, "Analytical Thermal Model for Fast Stator Winding Temperature Prediction," IEEE Transactions on Industrial Electronics, vol. 64, pp. 6116-6126, 2017.

[36] J. Pyrhonen, T. Jokinen, and V. Hrabovcova, Design of rotating electrical machines: John Wiley \& Sons, 2009.

[37] "U. S. Department of Energy; FY 2011 Vehicle Technologies Program Wide Funding Opportunity Announcement Funding Opportunity Number: DE-FOA-0000239," ed. 2011, pp. 17-18.

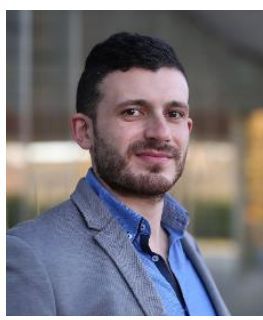

Vincenzo Madonna (S'17) received the BSc degree in Electronic Engineering from University of Calabria, Italy, in 2012, and the MSc degree in Electrical Engineering from the University of Bologna, Italy, in 2016. In 2012 he was an Exchange Student at KU Leuven, Belgium, and in 2015 he was a Visiting Researcher at the University of Nottingham, UK. He is currently a Marie Curie Researcher and $\mathrm{PhD}$ candidate in electrical machines design within the Institute for Aerospace Technology (IAT) and the PEMC group at the University of Nottingham, UK His research interests include design, thermal management and lifetime prediction modelling of electrical machines. Mr. Madonna received the qualification of Italian Chartered Engineer in 2016.

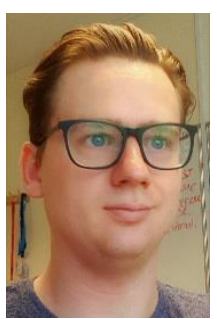

Adam Walker (M'18) received his $\mathrm{PhD}$ in electrical machines design from the University of Nottingham, UK, in 2016, where he has also worked as a Research Associate. He is currently an Assistant Professor of Electrical Machines and Drives with the Power Electronics Machines and Control group at the University of Nottingham. His main research area is electrical machines for traction applications, both personal vehicle and heavy duty vehicles, but is also interested in thermal management of machines and design of passive magnetic components.

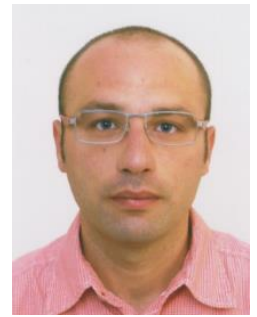

Paolo Giangrande received the Bachelor's (Hons.) and Master's (Hons.) degrees in electrical engineering at the Politecnico of Bari in 2005 and 2008, respectively. During 2008, he was a Marie Curie Intra-European Fellow at the University of Malta. He received his $\mathrm{PhD}$ in electrical engineering at the Politecnico of Bari in 2011. Since January 2012, he is Research Fellow at the University of Nottingham (UK), within the Power Electronics, Machines and Control Group. From 2017, he is the head of the Accelerated Lifetime Testing Laboratory at the Institute of Aerospace Technology, Nottingham. His main research interests include sensorless control of AC electric drives, design and testing of electromechanical actuators for aerospace, thermal management of highperformance electric drives and reliability and lifetime modelling of electrical machines.

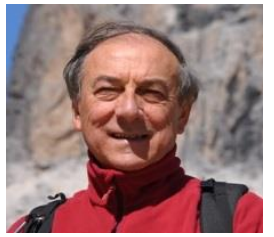

Giovanni Serra (SM'04) received the M.Sc. degree (with honors) in electrical engineering from the University of Bologna, Bologna, Italy, in 1975. $\mathrm{He}$ joined the Department of Electrical Engineering, University of Bologna as a Research Associate, then as an Associate Professor. Since 2001 is Full Professor of Electrical Machines and Electrical Drives with the Department of Electrical, Electronic, and Information Engineering "Guglielmo Marconi". He has authored more than 200 papers published in technical journals and conference proceedings. His research interests include electrical machines, electrical drives, and power electronic converters. His current research activities include multiphase drives, direct torque control of ac machines, linear motors, and ac/ac matrix converters. Prof. Serra is a member of the IEEE Industrial Electronics Society, IEEE Industry Applications, IEEE Dielectrics and Electrical Insulation Societies, and the Italian Electrotechnical and Electronic Association.

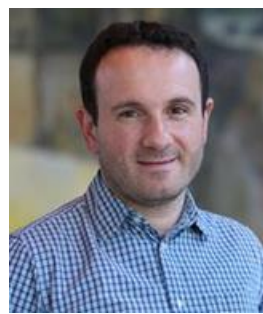

Chris Gerada (M'05-SM'12) received the Ph.D. degree in numerical modelling of electrical machines from The University of Nottingham, Nottingham, U.K., in 2005. He subsequently worked as a Researcher with The University of Nottingham on high-performance electrical drives and on the design and modelling of electromagnetic actuators for aerospace applications. In 2008, he was appointed as a Lecturer in electrical machines; in 2011, as an Associate Professor; and in 2013, as a Professor at The University of Nottingham. He was awarded a Research Chair from the Royal Academy of Engineering in 2013 and his main research interests include the design and modelling of high-performance electric drives and machines. Prof. Gerada serves as an Associate Editor for the IEEE TRANSACTIONS ON INDUSTRY APPLICATIONS and is the past Chair of the IEEE IES Electrical Machines Committee.

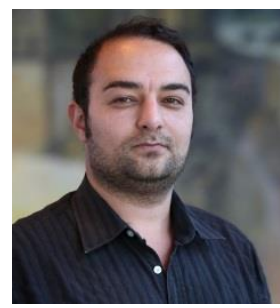

Michael Galea (M'13-SM'18, FRAeS) received his $\mathrm{PhD}$ in electrical machines design from the University of Nottingham, UK, where he has also worked as a Research Fellow. He is currently the Head of School of Aerospace in the University of Nottingham, Ningbo, China, where he is also the Director of Aerospace. He currently lectures in Electrical Drives and in Aerospace Systems Integration and manages a number of diverse projects and programmes related to the more / all electric aircraft, electrified propulsion and associated fields. His main research interests are design, analysis and thermal management of electrical machines and drives (classical and unconventional), the more electric aircraft and electrified and hybrid propulsion. He is a Fellow of the Royal Aeronautical Society and a Senior Member of the IEEE. 